\title{
Analysis of the Influence of Fuel on Oil Charge and Engine Wear
}

\author{
Michal Holubek ${ }^{1}$, Martin Pexa ${ }^{1}$, Jindrich Pavlu ${ }^{1}$, Jakub Cedík ${ }^{1}$, Katerina Vesela ${ }^{1}$, Peter Kuchar ${ }^{2}$ \\ ${ }^{1}$ Faculty of Engineering, Czech University of Life Sciences. Kamycka 129, 16500 Prague 6 - Suchdol. Czech Republic. \\ E-mail: holubekm@tf.czu.cz \\ ${ }^{2}$ Faculty of Engineering, Slovak University of Agriculture. Trieda Andreja Hlinku 609/2, 94901 Nitra. Slovak Republic.
}

\begin{abstract}
The combustion engine is a very widespread energy source for many machines and devices. Diesel, gasoline, LPG, CNG, as well as many biofuels such as ethanol, butanol, etc. are used as propellants at the present time. During the running of the internal combustion engine, some fuels penetrate into the crankcase and degrade the engine oil. This potentially reduces the lubricating ability of the oil and changes its degradation process. Submitted paper follows possible changes in lubricating capabilities of oil used in engines with specific fuels: n-butanol, LPG and diesel. Different type of fuel used in combination with an inappropriate operating mode might have a significant influence on the oil and consequently on the engine wear (monitored by a laser particle analyzer). This paper also deals with presence of various types of particles in the engine oil. Results demonstrate proceeding changes noticed in oil and also how was the degradation process effected.
\end{abstract}

Keywords: particles, lubrication, propellants, combustion engine, oil degradation

\section{Introduction}

The world demand for energy is expanding at a fast rate with the increasing trend of modernization and industrialization. Rapidly depleting petroleum resources and rising public concern related to climate change due to emissions associated with fossil fuel combustion has prompted much research into alternative energy resources. Consequently, strict legislation demands the automobiles to use more renewable fuels and n-butanol is one of those which take the most of attention. Nowadays, there are many types of standard and alternative fuels used for combustion engines and each of them has different influence on environment as well as on engine parts and oil charge $[10,12]$. One of the most important requirements for biofuels is to have similar chemical and physical properties as standard fuels have. However, alternative propellants will always have more or less different character (e.g. vapor pressure) of burning in combustion engine. A variety of fuels can be produced from plant biomass and fatty acids such as ethanol, methanol, butanol and biodiesel. Compared to conventional fossil fuels, biofuels have several advantages like the source of biofuel is renewable, combustion of biofuels produces less toxic compound and biofuels can reduce net carbon emissions up to a very low level $[4,9]$.

When the fossil or alternative fuels are used to propel the engine, the tribological effect on lubricant properties and performance of engine may appear. It is resulting from fuel dilution, thermic degradation or friction processes of moving parts of engine. There would be visible changes in oil structure and its lubrication capability and this state results into higher engine wear. During the combustion process, some amount of unburned fuel will impinge on the cold wall of the combustion chamber and then it will be scrapped into the crankcase of engine oil through cylinder liner. The piston ring and cylinder wall interface generally suffer from the most of engine friction and fuel dilution into the lubricant. It shall be noted that the impact of alternative fuels on lubricating oils proper- ties and performance is different from the gasoline or diesel $[5,6,11]$.

It has been observed that even a small amount of fuel dilution is possible to degrade the physicochemical properties of lubricant (viscosity, total base number, and total acid number) those have an important role in the lubricating system. When is lubrication oil degraded, the wear of combustion engine is excessive. Oil contamination is the most common and serious source of machine failure. Therefore, testing and analysis of lubrication oil is one of the most important condition monitoring techniques for machinery maintenance and failure diagnosis [7]. For this reason, research is focused on the observation and comparison of the tribological properties of the lubrication engine oil $[1,4,5]$. The aim of this paper is to probe engine oils used in different types of engines and find out if there is any remarkable influence on its contamination by particles and detect particle types distribution.

\section{Materials and methods}

In this experiment, there were three engines used and powered by different fuels: LPG, n-butanol and diesel. For long-term observation LPG engine was chosen in a passenger vehicle Škoda Felicia 1.3 MPi with engine modified from gasoline to LPG fuel usage and it was regularly maintained and oil filters were changed. Service interval for changing the oil charge was 15000 kilometres. The engine was powered by a 4-cylinder, 4-stroke OHV engine. Before the beginning of experiment, car had already driven 107898 kilometres. The producer recommended to use engine oil Mogul GX FE 10W-40 and the volume of oil was 3,5-4,5 litres in system. The engine oil filter was replaced approximately after each 8000 kilometres. During the experiment, engine oil sample was taken at a regular interval of about 500 kilometres with a volume of $100 \mathrm{ml}$. The car was operated in standard outside conditions, driven mostly in city traffic.

Second device was a small electric power generator from Briggs \& Stratton company, used as an engine for n-butanol fuel. This engine was completely new one. It 
can provide 2700 Watts of electric power. The engine configuration is $\mathrm{OHV}$ with single-cylinder. The manufacturer recommended to use oil from Briggs \& Stratton 5W30 , which was used. The replacement interval for oil is given to 50 operating hours cycle. Only during the run-in period, the first exchange interval is set to 5 hours. The oil sample was taken at a regular interval 10 hours with a volume of $20 \mathrm{ml}$ (a larger sample volume is not possible with a total engine oil volume of 0.7 liters). The generator was loaded with an electric power of 2000 Watts during operation, representing approximately $80 \%$ of its effective value in a room that has a constant temperature of 22 ${ }^{\circ} \mathrm{C} \pm 2{ }^{\circ} \mathrm{C}$. Due to the n-butanol fuel parameters (vapor pressure), the engine had to be running on the gasoline firstly and after brief heating-up it is switched to the test fuel. The combustion of the test fuel is close to the stoichiometric ratio 12: 1 (coefficient of excess air 1). The oil system in this generator does not have any filtration system with closed circulatory so contaminating particles are accumulating until the oil is refilled.

Diesel engine is installed in a passenger vehicle Citroen C3 Picasso with total volume of engine 1,6 HDi. It is 4-stroke, 4-cylinder engine. The type of oil recommended by producer is Total Quartz INEO ECS $5 \mathrm{~W}-30$ and volume of the oil was 3,75 litres in lubrication system. Service interval for oil refilling is 30000 kilometres. It was a brand new car in run-ning period while experimental sampling. The car was observed only during its first 10000 kilometres on roads. The friction processes were expected to be different for the new machine because of higher friction and wear level of moving parts. During the experiment, engine oil sample was taken at a regular interval of about 700 kilometres with a volume of $100 \mathrm{ml}$. The car was operated in standard outside conditions, driving mostly in city traffic.

Particle analyzer used for oil analysis was LaserNet Fines (LNF) which is one of the best devices for detecting different kind of particle in liquids [2, 7]. It is an optical system for automatic detection and identification of faults or incipient failure in mechanical systems due to excess mechanical wear, and for detecting contamination in hydraulic and fuel systems, and identifying underlying causes of that contamination. It is an analytical tool that combines the oil analysis techniques of particle size analysis and particle counting in one instrument. The LNF-C analyzes hydraulic and lubricating oil samples from various types of equipment and machinery that are part of a machine condition-monitoring program. LNF determines size distributions of wear particles in lubricating systems and classifies the particles according to the mechanical process responsible for their presence. The monitoring is based primarily on the morphological analysis and the particle size distribution of the abnormal wear particles that are created from the internal components of the machine. LNF utilizes a pulsed laser diode to form images of debris particles (visual in Fig. 1) in a flowing fluid system and computer image analysis and classification algorithms based on neural networks and fuzzy logic to determine the size and concentration of particles and identification of the mechanical wear processes associated with the particles from their shape characteristics. The operator is presented with an assessment of particles found in the fluid sample and a history of previous results for the same equipment.

LNF provides shape recognition of all particles greater than $20 \mu \mathrm{m}$ by using a neural network. An algorithm sorts particles into the following categories: abrasive, adhesive, fatigue, non-metallic and other fibres. The shape recognition software also does a test for circularity so that bubbles and droplets greater than $20 \mu \mathrm{m}$ are eliminated from the particle counting results [7].

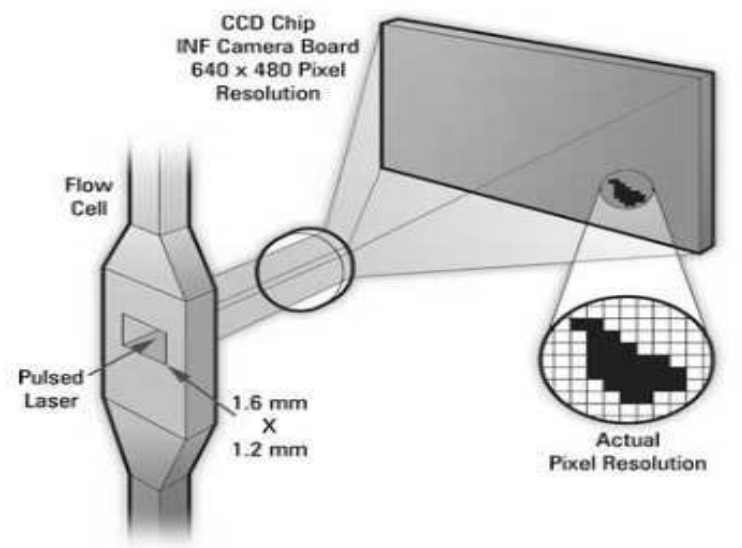

Fig. 1 Basic operation of LaserNet Fines [2]

As a particle counter, the LNF processes and stores thousands of images to obtain good counting statistics. Particles are sized directly and results can be displayed by ISO 4406 Code $(>4 \mu \mathrm{m},>6 \mu \mathrm{m}$, and $>14 \mu \mathrm{m})$, or several military codes. The direct imaging capability of this instrument eliminates the need for calibration with a test dust. Air bubbles greater than $20 \mu \mathrm{m}$ are ignored and the laser is powerful enough to process heavily contaminated (black) oils. It can also detect various types of particle for coming from different wear processes (abrasive, adhesive, fatigue, non-metallic or other types) [2].

\section{ISO Cleanliness Code 4406:1999}

\begin{tabular}{ccc}
\multicolumn{3}{c}{ ISO 4406:1999 Code Chart } \\
Range Code & $\begin{array}{c}\text { Particles per milliliter } \\
\text { More than }\end{array}$ & Up to / Including \\
\hline 24 & 80000 & 160000 \\
23 & 40000 & 80000 \\
22 & 20000 & 40000 \\
21 & 10000 & 20000 \\
20 & 5000 & 10000 \\
19 & 2500 & 5000 \\
18 & 1300 & 2500 \\
17 & 640 & 1300 \\
16 & 320 & 640 \\
15 & 160 & 320 \\
14 & 80 & 160 \\
13 & 40 & 80 \\
12 & 20 & 40 \\
11 & 10 & 20 \\
10 & 5 & 10 \\
9 & 2.5 & 5 \\
8 & 1.3 & 2.5 \\
7 & 0.64 & 1.3 \\
6 & 0.32 & 0.64 \\
& &
\end{tabular}

Fig. 2 ISO 4406:1999 Cleanliness Code Cart [8] 
The International Organization for Standardization created the cleanliness code 4406:1999 to quantify particulate contamination levels per milliliter of fluid at three sizes: $>4 \mu \mathrm{m},>6 \mu \mathrm{m}$, and $>14 \mu \mathrm{m}$. Each number represents a contaminant level code for the correlating particle size interval. The code includes all particles of the specified size and larger. It is important to note that each time a code increases the quantity range of particles doubles. In Fig.2, intervals for particles amounts per millilitre attached to each code number are shown [8].

\section{SVM 3000 Stabinger Viscometer}

For the LPG engine only there was measured dynamic a kinematic viscosity as well. "The SVM 3000 Stabinger Viscometer measures the dynamic viscosity and density of oils and fuels according to ASTM D7042. From this result, the viscometer automatically calculates the kinematic viscosity and delivers measurement results which are equivalent to ISO 3104 or ASTM D445. The Stabinger measuring principle with Peltier thermostat enables an incomparably wide viscosity and temperature range with a single system. The thermostat works with high-precision stability of $0.005^{\circ} \mathrm{C}$. SVM 3000 is quick, compact and energy-saving, versatile in use, with only small amounts of sample and solvents required. It can measure up to 30 samples per hour. From 2.5 millilitres sample volume (from 1 milliliter without density measurement). This device uses an unique measuring principle. The measuring cell contains a tube filled with sample which rotates at a constant speed. In this tube floats a measuring rotor. The result is the first rotational viscometer which completely eliminates the influence of bearing friction", in [3].

\section{Results and discussion}

Following graphs and figures show measured amounts of particles by ISO 4406:1999 detected in engine oils used for LPG, n-butanol and diesel engine. Each engine worked in various circumstances and running modes. Moreover, there are also percentage distributions of various particles (abrasive, adhesive, fatigue, non-metallic and other fibres) calculated three times for each engine to show how the structure of contaminants was changed. For LPG engine only dynamic and kinematic viscosity is shown.

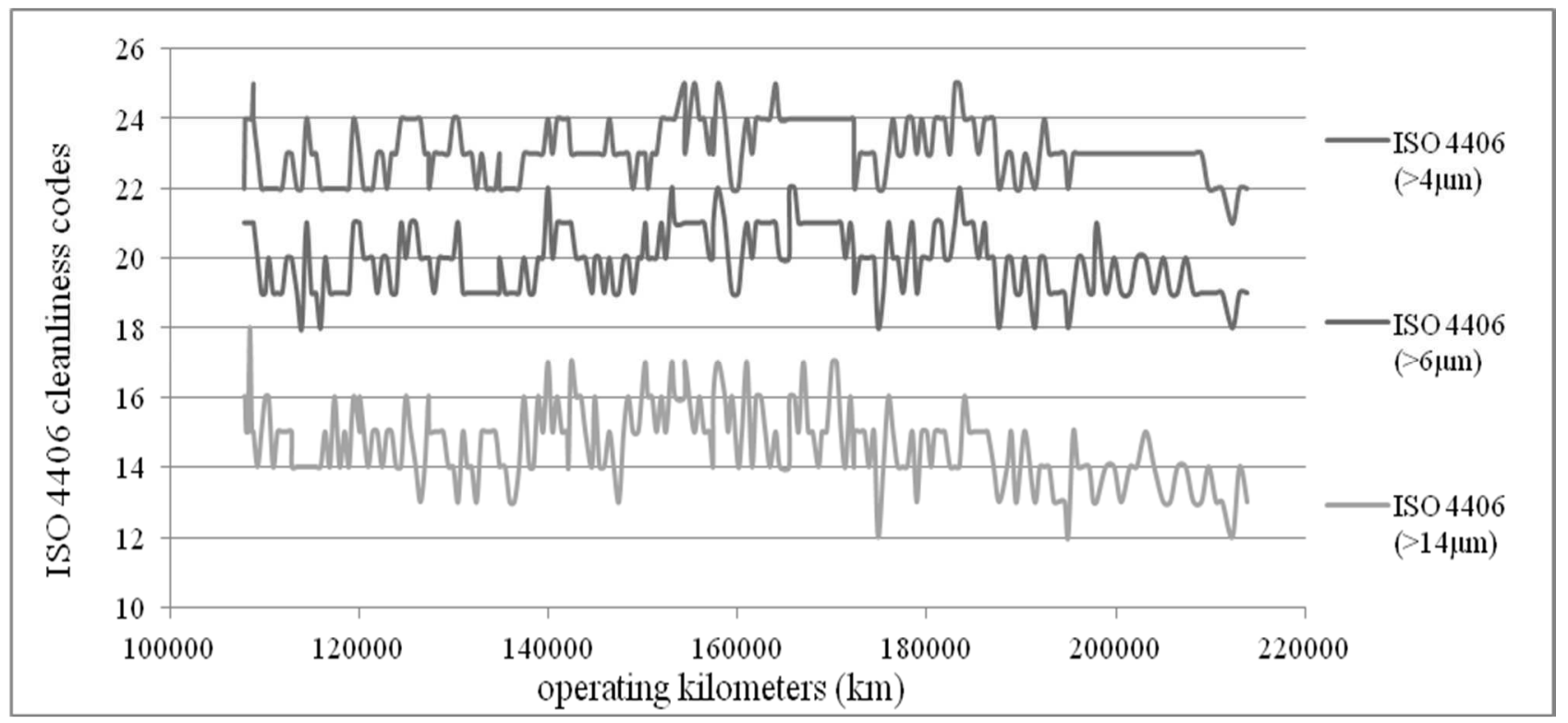

Graph 1 Škoda Felicia (LPG engine): particles in oil according to ISO4406

In the Graph 1 results of experiment with LPG engine made out of 210 samples during operating period approximately 105000 kilometres are stated and sampling had been done each 500 kilometres. Three curves are representing particles of different size by ISO 4406 Code $(>4 \mu \mathrm{m},>6 \mu \mathrm{m}$, and $>14 \mu \mathrm{m})$, as is stated in description of graph. From graph is evident that highest amount of particles is in category $>4 \mu \mathrm{m}$ and the lowest amount is in category $>14 \mu \mathrm{m}$. The curves are oscillating in range of $4-$ 5 cleanliness codes. The engine has been regularly maintained and the oil filters substituted in intervals around 8000 kilometres. Total amount of particles did not gradually increase in any operating period of the engine. Particles of any type did not accumulate in the oil significantly. Contrary, the trend was slightly decreasing. The trend of curves was effected by maintainance period, replacing filters and driving modes, too.

Additionally, in the Graph 2 measured values of dynamic and kinematic viscosity of the oil used in LPG engine are presented. Viscosity was measured at $40^{\circ} \mathrm{C}$ and $100{ }^{\circ} \mathrm{C}$ for each sample. Here is also not visible any significant change during any part of operating period and functional curve is linear without extremes in increasing and decreasing parts which would indicate change in lubrication characteristics of oil. Due to the fact that no serious influence has been noticed even during long-term observation, viscosity was not measured for another two engines with short-term experiment (n-butanol and diesel). 


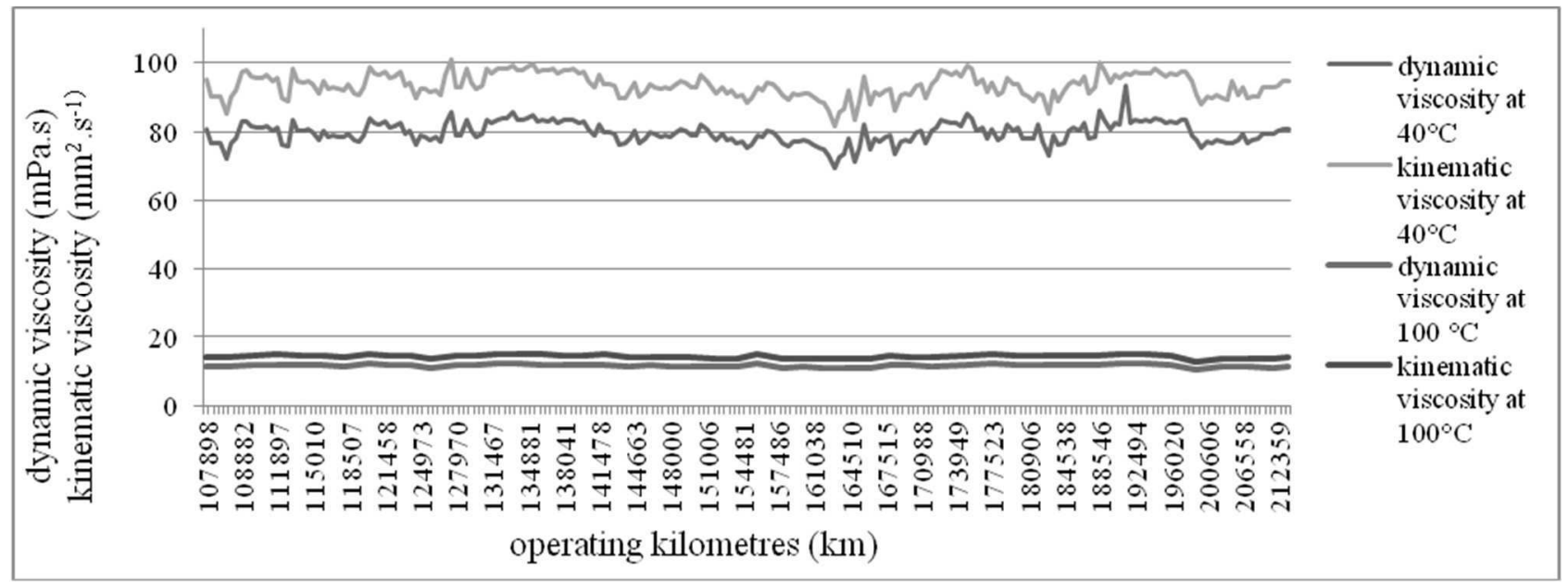

Graph 2 Škoda Felicia (LPG engine): dynamic and kinematic viscosity of oil at $40^{\circ} \mathrm{C}$ and $100^{\circ} \mathrm{C}$

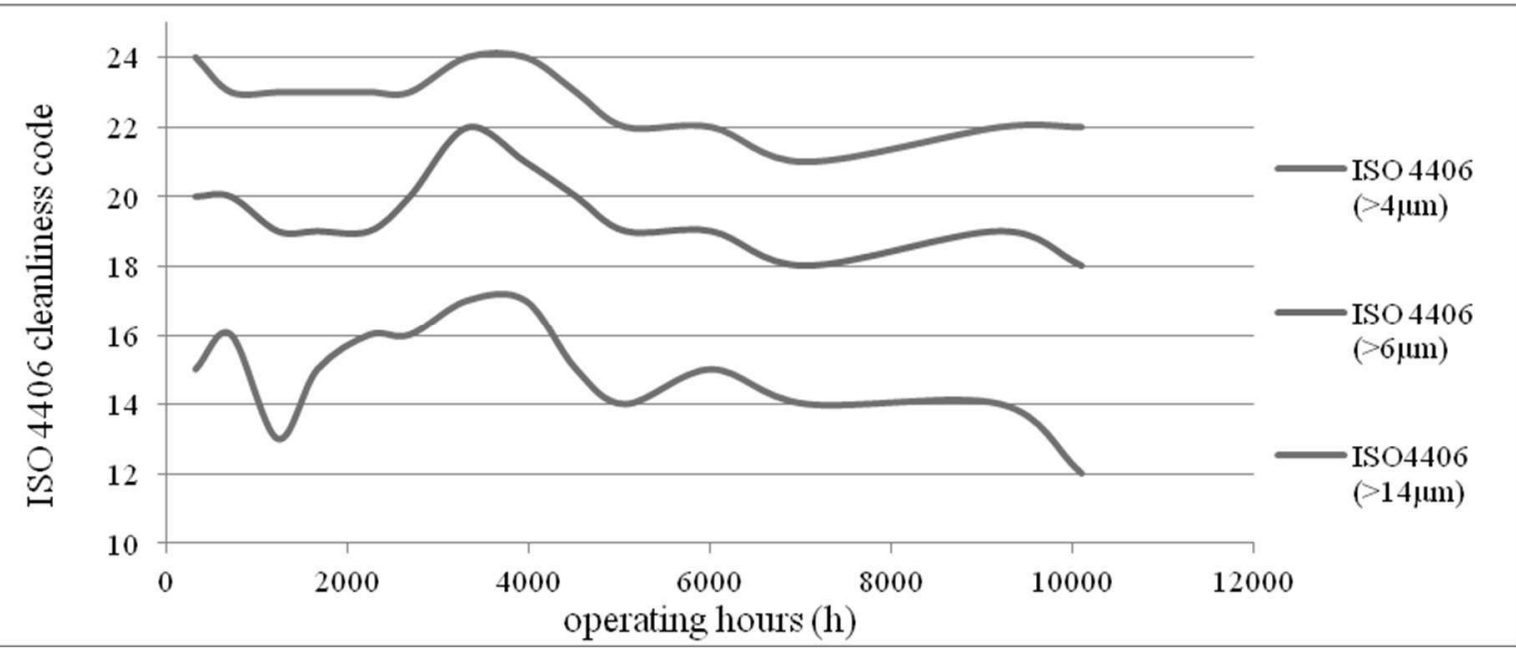

Graph 3 Citroen (diesel engine) - particles in oil according to ISO4406

From the point of view of the total number of particles present in the engine oil, it can be stated according to Graph 3 that after the first samples (run-in period), the number of particles increased to the maximum after around 4000 operated kilometres. At this point cleanliness codes for all three particles sizes increased, because the particles have been accumulated in new diesel engine. Wear and friction processes are more evident when monitoring a brand new engine. However, filtration system separated the contaminating particles and curves were slowly decreasing to its lowest point at the end of experiment.

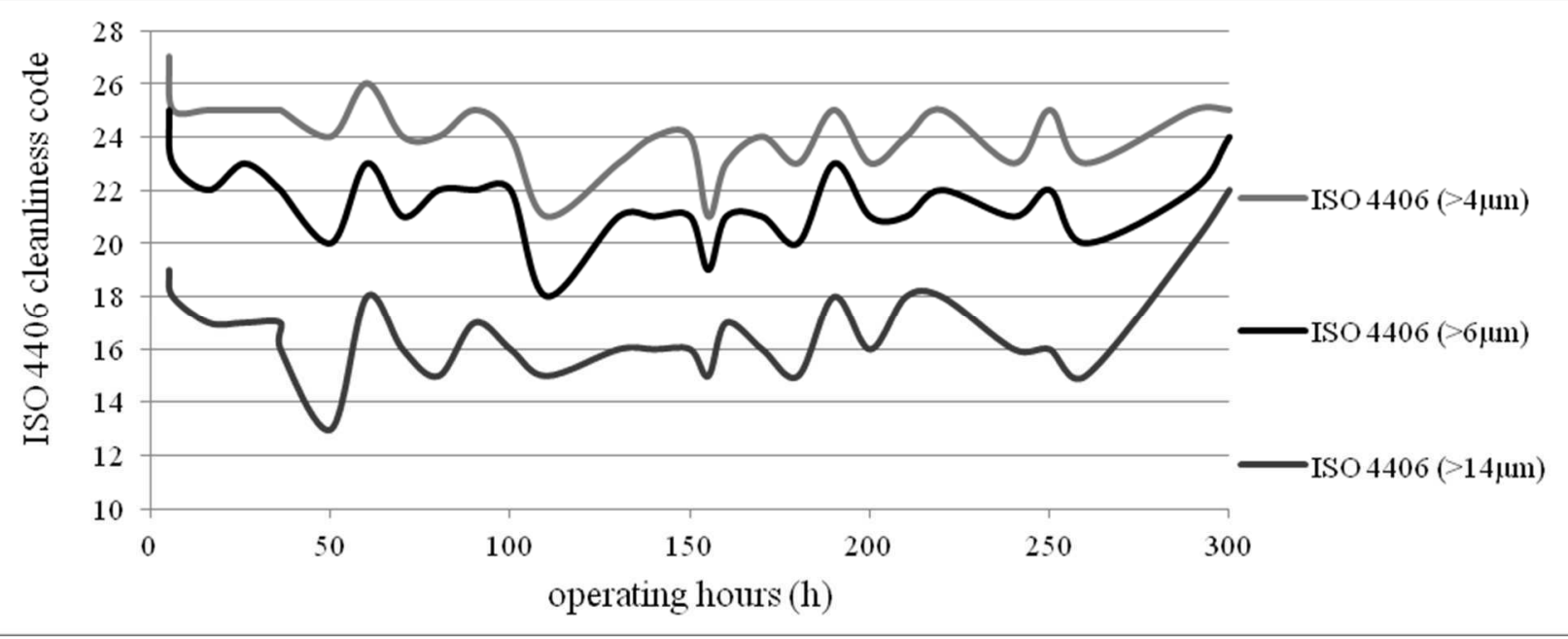

Graph 4 Electric generator (n-butanol engine) - particles in oil according to ISO4406 
According to Graph 4 total number of particles is gradually increasing in the interval 250 - 300 operating hours. In this case the engine powered by n-butanol fuel was constructed in the way, that there is no filtrating system of oil. The volume of oil remains the same until it is refilled. Consequently, there is visible increase of particles in the interval $250-300$ hours, although the oil was refilled each 50 operating hours. There might be eventually incorrect running modes of engine or over-heating of the oil causing this change. Considering this fact, there is increasing total number of particles of all sizes and the engine oil charge needed to be refill and engine maintained.

In following diagrams it is shown how percentage distribution of various types of particles is modified (abrasive, adhesive, fatigue, non-metallic and other fibres) during the experiment period. For each engine comparison of three distributions was made. Samples were divided into three thirds according to the length of experiment for each of them.
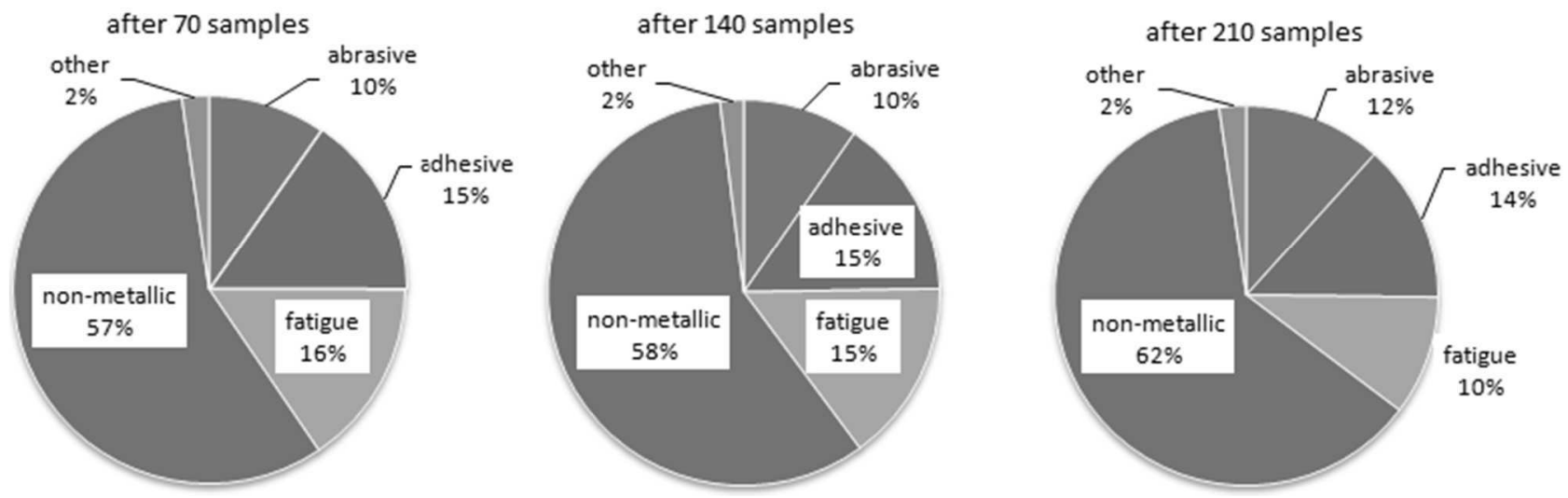

Fig. 3 Changes in distribution of various particle types during the experiment with LPG engine - after 70, 140, and 210 samples

Diagrams in Fig. 3 represent percentage distribution for total numbers of detected elements in oil used in engine powered by LPG fuel. Distribution was calculated after 70 samples, 140 samples and 210 samples. By Fig. 3 gradually increasing amount of non-metallic particles (from $57 \%$ to $62 \%$ ) and decreasing ratio of particles caused by fatigue wear (from $16 \%$ to $10 \%$ ) are noticed. Abrasive particles are slowly increasing as well. It may be caused by thermic and friction degradation of the oil as well as polluting matter.
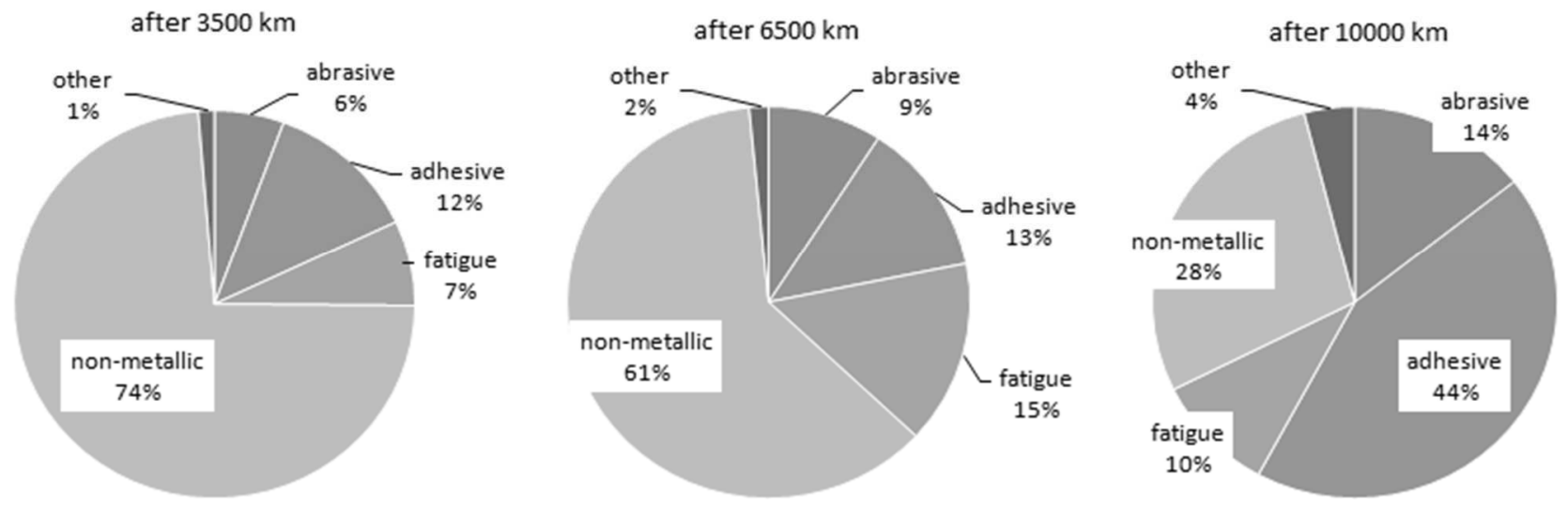

Fig. 4 Changes in distribution of various particle types during the experiment with diesel engine - after 3500, 6500 and 10000 operating kilometres

In the Fig. 4 changing percentage distribution structure of particles while running the brand new diesel engine is significantly visible. At the beginning, non-metallic particles are dominant with three quarters partition, but sharply descending (from $74 \%$ to $28 \%$ ) because other particles became more extensive. After 10000 kilometres there is $32 \%$ increase of adhesive particles and $8 \%$ increase of abrasive particles. It means that moving parts of running engine were exposed to friction processes and this most likely causes the difference in oil structure for new engine.

In Fig. 5 percentage distribution of various particles in small electric generator filled by n-butanol as a biofuel is stated. Sampling was realized during its 300 operating hours after each 10 hours. After 100 hours the distribution of particle types was balanced because the engine was brand new without any previous usage. Later after operating 200 hours there was $33 \%$ increase in amount of nonmetallic particles in compare to other ones and after 300 hours even $8 \%$ more and it takes very dominant proportion (in total $41 \%$ increase). It may be caused by thermic degradation of the oil which effects creating of gel resin particles. Contribution of abrasive, adhesive and fatigue particles decreased significantly (19\% decrease of fatigue particles is the most noticeable). 

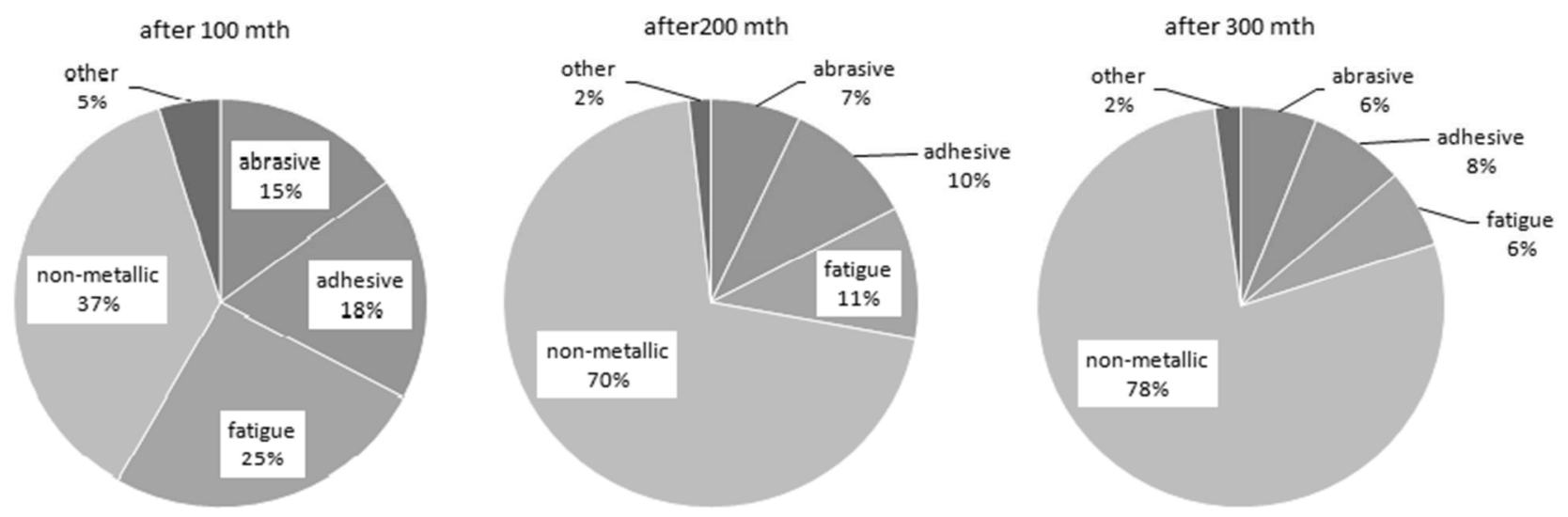

Fig. 5 Changes in distribution of various particle types during the experiment with n-butanol engine - after 100, 200 and 300 operating hours

\section{Conclusion}

In this paper three different engines powered by LPG and diesel as for standard fuels and n-butanol as a biofuel were followed. Each engine operated in various running modes. The main aim of our experiment was to find out if there was any coherence between fuel type and engine oil degradation process. In LPG engine was performed a long-term observation. Oil was sampled each 500 kilometres (in total 210 samples). Other two engines, with n-butanol and diesel, they were brand new and here the very beginning of their functional life was observed. For n-butanol engine was observed first 300 operating hours (sampling each 10 hours) and for diesel engine it was first 10000 kilometres (sampling each 700 kilometres).

From the point of view of particles amount, there was not found any significant change in oil caused by using different types of fuel in engine. The particles amounts observed according to ISO 4406:1999 did not show any tendency of accumulating in oil used for LPG engine (in Graph1). Viscosity also remained the same (Graph 2). This result opposes to original ideal of authors who expected considerable transformation in oil composition. However, in n-butanol (Graph 4) and diesel engine (Graph 3) slow increasing of particles at some samples was noticed, most likely because of new moving parts of engine which influenced contamination of oil by friction processes as well as maintainance intervals. On the other hand, type of fuel does not seem to be relevant and changes are explainable by other effects.

Changes in distribution of various particle types during the experiment shown in Fig.3, Fig.4, and Fig.5 are much more evident. There were compared different types of particles (adhesive, abrasive, fatigue, non-metallic and other fibres) in term of their percentage distribution in oil. Especially content of non-metallic particles has markedly increased in n-butanol from $37 \%$ to $78 \%$ (Fig. 5) and in LPG $57 \%$ to $62 \%$ (Fig. 3) engines, likely caused by thermic degradation of oil and contaminants. Moreover, in diesel engine amount of adhesive particles from $12 \%$ to $46 \%$ (Fig. 4) increased which might be cause by friction process. Most of the indicated changes observed in oils are consequences of their usage in various conditions (engines) depending on physical effects (friction, heat, pressure) and contamination. Influence of different types of fuels was not proved by this experiment.

\section{Acknowledgements}

The paper was created with the grant support-CULS IGA 2017: 31190/1312/3119 - Analysis of the impact of biofuels on the pressure profile in the combustion chamber of turbocharged diesel engine and project CULS CIGA 2017 - 20173001 - Utilization of butanol in compression ignition engines of generators.

\section{References}

[1] AlES, Z., PAVLU, J., SVOBODOVA, J., KUCERA, M., HROMASOVA, M., PEXA, M. (2017). Impact of contaminants in motor oil on the wear of aluminium parts of the internal combustion engine. In: Manufacturing Technology. Vol. 17, No. 5, pp. 647 - 652. Institute of Technology and Production Management University of J.E. Purkyne, Usti nad Labem.

[2] FILICKY, D., SEBOK, T., MATLE, L., ANDERSON, D. (2002). Laser Net Fines - A New Tool for the Oil Analys is Toolbox. In: Practicing Oil Analysis. Vol. 9. Noria, USA.

[3] FITCH, B. (2013). Anatomy of a Viscometer. In: Machinery Lubrication. Vol. 8. Noria, USA.

[4] JANOSKO, I., JABLONICKY, J., HUJO, L., KUCHAR, P. (2017). Evaluation of the impact of diesel fuel additive on selected combustion engine parameters. In: KOKA, pp. 213-221. Technical University, Liberec.

[5] KHUONG, L.S., MASJUKI, H.H., ZULKIFLI, N.W.M., NIZA MOHAMAD, E., KALAM, M.A., ALABDULKAREM, A., ARSLAN, A., MOSAROF, M.H., SYAHIR, A.Z., JAMSHAID, M. (2017). Effect of gasoline-bioethanol blends on the properties and lubrication characteristics of commercial engine oil. In: RSC Advances. Vol. 7, 
No. 25, pp. 15005 - 15019. Royal Society of Chemistry, London.

[6] KRALIK, M., JABLONICKY, J., TKAC, Z., HUJO, L., UHRINOVA, D., KOSIBA, J., TULIK, J., ZAHORSKA, R. (2016). Monitoring of selected emissions of internal combustion engine. In: Research in Agricultural Engineering. Vol. 62, pp. 66 - 70. Czech Academy of Agricultural Sciences, Prague.

[7] KUCERA, M., ALES, Z., PEXA, M. (2016). Detection and characterization of wear particles of universal tractor oil using a particles size analyzer. In: Agronomy Research. Vol. 14, No. 4, pp. 1351 - 1360. Estonian University of Life Sciences, Estonia.

[8] ISO 4406 : 1999 . Hydraulic fluid power - Fluids Method for coding the level of contamination by solid particles.

[9] MULlEROVA, D., JABLONICKY, J., HUJO, L., KOSIBA, J., TKAC, Z., KRALIK, M., CHRASTINA, J. (2013). Research of limited and unlimited emission effect on the environment during the burning of alternative fuels in agricultural tractors. In: Journal of Central European Agriculture. Vol. 14, No. 4, pp. 1419 - 1431. International Editorial Board of the Journal of Central European Agriculture, Slovakia.

[10] OUMER, A.N., HASAN, M.M., BAHETA, A.T., MAMAT, R., ABDULLAH, A.A. (2018). Biobased liquid fuels as a source of renewable energy: A review. In: Renewable and Sustainable Energy Reviews. Vol. 88, No. 5, pp. 82 - 98. Elsevier, Netherlands.

[11] PAVLU, J., HONIG, V., ALES, Z., CHOTEBORSKY, R. (2016). Tribodiagnostic analysis of motor oil after failure of turbocharger of combustion engine. In: Manufacturing Technology. Vol. 16, No. 5, pp. 1115 - 1122. Institute of Technology and Production Management University of J.E. Purkyne, Usti nad Labem.

[12] VERMA, P., ZARE, A., JAFARI, M., BODISCO, T.A., RAINEY, T., RITKOVSKI, Z.D., BROWN, R.J. (2018). Diesel engine performance and emissions with fuels derived from waste tyres. In: Scientific Reports, Vol. 8, No. 1. Nature Publishing Group, Australia. 